\title{
STABILITY OF REGIONAL SHARE COMPONENTS?
}

\author{
JoHN A. KuEHN*
}

A major criticism of utilizing shift and share analysis for projecting economic growth, as opposed to its use as an index of past economic activity, focuses on the stability of the regional share component. If this component fails to- exhibit stability over time, then predictive techniques incorporating such historical data may be subject to error. Using chi-square tests of sign changes, Brown concluded that regional share components for various manufacturing sectors in selected metropolitan areas were unstable (2). Paraskevopoulos countered that his analysis of sign changes revealed that total regional share components by counties evidenced stability over time (6). Floyd and Sirmans, utilizing data for states and tests of sign changes, also maintained that regional share components were stable both in total and for various industries (3). James and Hughes' predictive model incorporating regional share data for twenty manufacturing industries by states revealed that usage of such data contributed to the accuracy of short-term projections for a majority of the industries (4).

This comment presents an additional test of the stability of regional share components in total and by industrial sectors for the periods 1940-50, 1950-60, and 1960-70. Employment data by industrial sectors were obtained from the U.S. Censuses of Population for all 372 counties in Arkansas, Kansas, Missouri, and Oklahoma. This four state area included most of the Ozarks Economic Development Region. Disaggregation by county and industrial sectors was considered appropriate because the utility of predictive models increases with disaggregation and because analysis of averages and aggregated data may encounter biases and problems of statistical inference $(1 ; 3$, p.119; 7$)$. Regional shares by industry were calculated using national growth rates as the base so that regional shares represent the amounts by which each industry's growth exceeded or fell below the same industry's national growth rate.

The specific test employed in this analysis was Pearson's coefficient of determination $\left(\mathrm{r}^{2}\right)$. If simple linear regressions were computed for respective regional share components between decades, then the coefficient of determination has the familiar interpretation of being the proportion of one variable's variance which is explained by the linear influence of another variable. In table 1 , for example, only 8 percent of the variance for agriculture's regional share in 1950-60 can be explained by a linear relationship with agriculture's regional share in 1940-50. Coefficients of determination directly measure the magnitude of stability for regional shares between decades whereas analysis only of sign changes presents substantially less information. Large coefficients of determination for each pair of decades compared would be indicative of stability for an industry's regional share component. Tests of significance are deliberately omitted insofar as

\footnotetext{
*Agricultural Economist, Economic Research Service, U.S. Dept. of Agriculture, University of Missouri-Columbia.
} 
two-tailed tests for the hypothesis that $r$ equals zero have little importance. More appropriate would be one-tailed tests for the hypothesis that $r$ equals or exceeds some predetermined, desired proportion of variance explained. If r's were judged significant, then regression coefficients could be utilized to improve estimates of regional share components.

\section{TABLE 1: Measures of Stability of Regional Share Components}

\begin{tabular}{|c|c|c|c|}
\hline \multirow{2}{*}{ Regional Shares by Sectors } & \multicolumn{3}{|c|}{$\begin{array}{c}\text { Coefficients of Determination- } \\
\text { Pearson's r }{ }^{2}\end{array}$} \\
\hline & $\begin{array}{c}1940-50 \\
\text { versus } \\
1950-60\end{array}$ & $\begin{array}{c}1950-60 \\
\text { versus } \\
1960-70\end{array}$ & $\begin{array}{c}1940-50 \\
\text { versus } \\
1960-70\end{array}$ \\
\hline Agriculture, Forestry, and Fisheries & .083 & .098 & .005 \\
\hline Mining & .085 & $(-) .000$ & $(-) .032$ \\
\hline Construction & .135 & .462 & .243 \\
\hline Food and Kindred Products Mfg. & .527 & .629 & .542 \\
\hline Apparel and Textiles Mfg. & .650 & .395 & .429 \\
\hline Furniture, Lumber, Wood Products Mfg. & $(-) .000 \mathrm{a}$ & .108 & .125 \\
\hline Printing and Publishing Mfg. & .641 & .594 & .482 \\
\hline Chemicals and Allied Products Mfg. & .405 & .466 & .280 \\
\hline Machinery Mfg. & .828 & .533 & .552 \\
\hline Transportation Equipment Mfg. & .623 & $(-) .040$ & $(-) .402$ \\
\hline Metal Industries Mfg. & .669 & .044 & .074 \\
\hline Miscellaneous Manufacturing & .670 & .535 & .469 \\
\hline Railroads and Railway Express & .487 & .589 & .177 \\
\hline Trucking and Warehousing & .128 & .722 & .164 \\
\hline Other Transportation & .522 & .185 & .004 \\
\hline Communications & .541 & .519 & .590 \\
\hline Utilities and Sanitary Services & $(-) .007$ & .311 & $(-) .110$ \\
\hline Wholesale Trade & .608 & .343 & .038 \\
\hline Food and Dairy Stores & .795 & .646 & .521 \\
\hline Eating and Drinking Places & .824 & .609 & .414 \\
\hline Other Retail Trade & .893 & .820 & .685 \\
\hline Finance, Insurance, Real Estate & .887 & .831 & .862 \\
\hline Hotels and Other Personal Services & .853 & .719 & .481 \\
\hline Private Households & .188 & .033 & .006 \\
\hline Business and Repair Services & .624 & 647 & .709 \\
\hline Entertainment and Recreation Services & .364 & .428 & .553 \\
\hline Professional and Related Services & .371 & .748 & .295 \\
\hline Public Administration & .079 & .367 & .022 \\
\hline Armed Forces & $(-) .041$ & $(-) .070$ & .001 \\
\hline Total Regional Share & .864 & .857 & .720 \\
\hline
\end{tabular}

$\mathrm{N}=372$ counties in Arkansas, Kansas, Missouri, and Oklahoma.

aMinus sign in parentheses indicates coefficient of correlation was negative. Three zeros indicate that $\mathrm{r}^{2}$ was less than 0.001 but not equal to 0 .

Results in Table 1 indicate that considerable stability was evident for total regional share components and also for the separate industries of other retail trade and finance, insurance, real estate. The proportion of variance explained between successive decades exceeded 80 percent in these cases as noted by the size of the coefficients in each comparison between decades. Other industries where the 
TABLE 2: Measures of Convergence of Regional Share Components

\begin{tabular}{|c|c|c|c|}
\hline \multirow{2}{*}{ Regional Shares by Sectors } & \multicolumn{3}{|c|}{ Standard Deviation } \\
\hline & $1940-50$ & $1950-60$ & $1960-70$ \\
\hline Agriculture, Forestry, and Fisheries & 448 & 304 & 258 \\
\hline Mining & 226 & 164 & 205 \\
\hline Construction & 528 & 479 & 324 \\
\hline Food and Kindred Products Mfg. & 135 & 687 & 258 \\
\hline Apparel and Textiles Mfg. & 146 & 248 & 215 \\
\hline Furniture, Lumber, Wood Products Mfg. & 180 & 116 & 100 \\
\hline Printing and Publishing Mfg. & 126 & 240 & 207 \\
\hline Chemicals and Allied Products Mfg. & 123 & 271 & 188 \\
\hline Machinery Mfg. & 305 & 698 & 805 \\
\hline Transportation Equipment Mfg. & 532 & 811 & 740 \\
\hline Metal Industries Mfg. & 137 & 526 & 365 \\
\hline Miscellaneous Manufacturing & 506 & 793 & 634 \\
\hline Railroads and Railway Express & 77 & 177 & 150 \\
\hline Trucking and Warehousing & 58 & 228 & 187 \\
\hline Other Transportation & 186 & 189 & 187 \\
\hline Communications & 82 & 143 & 121 \\
\hline Utilities and Sanitary Services & 85 & 141 & 126 \\
\hline Wholesale Trade & 443 & 644 & 504 \\
\hline Food and Dairy Stores & 238 & 251 & 221 \\
\hline Eating and Drinking Places & 221 & 291 & 300 \\
\hline Other Retail Trade & 669 & 1,044 & 854 \\
\hline Finance, Insurance, Real Estate & 282 & 565 & 476 \\
\hline Hotels and Other Personal Services & 302 & 317 & 239 \\
\hline Private Households & 112 & 199 & 66 \\
\hline Business and Repair Services & 169 & 199 & 241 \\
\hline Entertainment and Recreation Services & 59 & 58 & 72 \\
\hline Professional and Related Services & 368 & 882 & 1,176 \\
\hline Public Administration & 511 & 542 & 394 \\
\hline Armed Forces & 606 & 1,411 & 469 \\
\hline Total Regional Share & 4,558 & 9,733 & 7,334 \\
\hline
\end{tabular}

$\mathrm{N}=372$ counties in Arkansas, Kansas, Missouri, and Oklahoma.

proportion of variance explained exceeded 50 percent included food, printing, machinery, and miscellaneous manufacturing; communications; food and dairy stores; eating and drinking places; hotels and other personal services; and business and repair services. For the remaining 18 sectors, little or no stability was evident. Furthermore, the degree of stability differed depending upon the decades compared; that is, coefficients of determination by industry varied by decades compared. In general, stability was greater between successive decades than for the comparison between 1940-50 and 1960-70.

Floyd and Sirmans also stated that assuming respective regional share components are converging among areas improves the predictive ability of the shift-share model (3, p. 119). Actually, if convergence were complete, the shift-share model applied to all constituent areas within the spatial base would be identical to the Super Ingrow model used by Brown. Floyd and Sirmans assumed convergence on the basis of relative percentage measurements. An accurate 
measure of actual convergence is the standard deviations of the frequency distributions of regional share components compared over time (5). Table 2 shows that convergence from 1940 to 1970 was obtained only in three industries: namely, agriculture, forestry, fisheries; construction; and furniture, lumber, wood products manufacturing. For all other industries and also in total, convergence was not evident; standard deviations either increased or fluctuated from the 1940 decade to the 1960 decade.

For the 372 counties of Arkansas, Kansas, Missouri, and Oklahoma, regional share components exhibited varying degrees of historical stability, or conversely, instability. Only 7 industrial sectors and the total summation had coefficients of determination exceeding 50 percent for all comparisons by decades between 1940 and 1970. Individual researchers need to determine for themselves acceptable levels of instability. Moreover, the hypothesis of converging regional shares over time did not appear realistic in the region under study. There were only 3 industries with successively converging regional shares between 1940 and 1970 . Usage of regional share components to improve employment projections for small areas like counties does not appear warrented. It is possible that other areas of the Nation may exhibit different patterns of stability and convergence.

\section{REFERENCES}

(1) Abel, Martin E. and Frederick V. Waugh. "Relationships between Group Averages and Individual Observations." Agricultural Economics Research, 48 (1966), 105-115.

(2) Brown H. J. "Shift and Share Projections and Regional Economic Growth: An Empirical Test," Journal of Regional Science, 9 (1969), 1-18.

(3) Floyd, Charles F. and C. F. Sirmans. "Shift and Share Projections Revisited," Journal of Regional Science, 13 (1973), 115-120.

(4) James, Franklin, Jr. and James Hughes. "A Test of Shift and Share Analysis as a Predictive Device," Journal of Regional Science, 13 (1973), 223-231.

(5) Kuehn, John A. "Income Convergence-A Delusion," Review of Regional Studies, Vol II, No. 1 (1971), 41-52.

(6) Paraskevopoulos, Christos C. "The Stability of the Regional-Share Component: An Empirical Test," Journal of Regional Science, 11 (1971), 107-114.

(7) Sawicki, David S. "Studies of Aggregated Areal Data: Problems of Statistical Inference,"Land Economics, 49(1973), 109-114 